\title{
Military Psychology- Need, Scope and Challenges
}

\author{
Mansi Sharma ${ }^{1 *}$
}

\section{ABSTRACT}

The history of military psychology dates back to the times of World War I and World War II when army Alpha and army beta tests were constructed by psychologists. The army Alpha test was constructed by Robert Yerkes along with his colleagues in the year 1917 to evaluate The US military recruits during World War I. The aim of this research is to understand, evaluate the need of military psychology and its scope and challenges face by the armed forces of India. With this research article, the aim is also to highlight the qualitative relationship of psychology and military culture. With this paper the author aims to analyze how the Indian military culture functions and what role psychology plays in its functioning. The armed forces have always displayed its zeal, sheer wit and courage in strengthening the structure of Democratic country like India. The attempt is to explore in depth, the need of military psychology and how military psychologists or psychologists in general can help the military personnel during times of psychological distress. This research also provides ways in which the mental health professionals can strengthen this relationship with the armed forces of India.

Keywords: Military Psychology, Indian Armed Forces, Psychological Assessment, Trauma.

$\mathrm{M}$ ilitary psychology can be defined as a sub specialization field of psychology that deals with promoting the readiness, resilience, altruism of military personnel in training, research and analysis and operations by applying the principles of psychological sciences. As far as clinical military psychology is concerned, it deals with proving psychological intervention for mental health issues, psychological preparedness and traumatic experiences, usually in a clinical setting.

\section{History of Military Psychology}

the history of military psychology dates back roughly to about 100 years when the onset of the World War I demanded an immediate and rapid increasing the military personnel even though as a reserved base from 1,90,000 to about 3,65,000 roughly in about two years. A national research commission of the US proposed in 1917 that, there should be an immediate recruiting of psychologists to evaluate and understand the effects of mass undertrained recruitment on the mental health of the military personnel.

${ }^{1}$ Counselling Psychologist, Uttar Pradesh, India

*Corresponding Author

Received: May 14, 2021; Revision Received: May 23, 2021; Accepted: June 21, 2021

(C) 2021, Sharma M.; licensee IJIP. This is an Open Access Research distributed under the terms of the Creative Commons Attribution License (www.creativecommons.org/licenses/by/2.0), which permits unrestricted use, distribution, and reproduction in any Medium, provided the original work is properly cited. 
Following the proposal, Robert Yerkes, the president of the American Psychological Association was appointed as the Major in the US armed forces. This also paved way for the first active recruitment of 16 psychologists as first Lieutenants. Skeptical of Yerkes's theoretical approach, Walter Scott and Walter Bingham wanted to devise a business oriented and a practical approach to military recruitment and training. The navy backed off but psychologists soon became active in training and recruitment of aviation personnel.

After a successful trial, a standardized procedure was followed at the training camp in Georgia, using the army alpha tests for the literate and the army beta tests for the military personnel and technicians as proposed and required by the US. By the end of 1918, about 24 odd companies had psychological assistance.by the time World War I was concluding several psychological postings were asked to include clinical testing, forensics and strategizing psychiatric advancement.

By the time there was a sight of World War II, the positive experiences gathered from the first war were enough to move forward progressively. Around 140 psychology officials were commissioned as the first and the second lieutenants respectively. Although the Army Research Institute for behavioral sciences was established in 1939, the aviation psychologists were recruited officially in 1941. The Stanford Binet Intelligence Scale, Wechsler-Bellevue scale and the Army Classification Test were officially accepted as Intelligence tests to be used for the US armed forces.

It is surprising to know that the Rorschach and Wechsler's intelligence scale were first administered on 56 senior surviving Nazi leaders during their classified operation. The recruits who most needed psychological attention was either the ones tortured by the Philippines or the aircrews. Some of the other troops needing psychological intervention were the prisoners of war held by the Japanese soldiers on duty during the World War II. Most of the treatment conducted which was intensive in nature was taken care of in the hospitals of the US. By the end of the war, Edward Boring, who served under the able leadership of Yerkes, conceptualized a seven-pointer bifurcating the psychological divisions of the US army and the US navy, some of the battalions still swear by-

- Observation- accurate perception

- Performance- work efficacy, skill- acquisition, momentum and an action-oriented approach.

- Selection- choosing the right man for the right job by classification.

- Training - transforming attitudes into accomplished skills.

- Personal adjustment- the will and vigor of an individual to deal with the military life and work culture.

- Social relations- leadership qualities and the relationship the recruits should have with people of varied castes and ethnicities.

- Opinion and propaganda- the art of psychological warfare, decision making and task orientation.

In February 1946, the Military Neuropsychiatry school was shifted to Brooke General hospital where the chief clinical psychologist was commissioned to administer the operations, creating a pathway to the establishment of the $19^{\text {th }}$ division of the APA, military psychology sprouted from the American Association of Applied Psychology. 
The Korean peninsula saw the recruitment of the psychologists in commission or service oversees. This time the effort was to manage and address the combat stress related principles. Due to this algorithm the return rates increased of 40 percent in World War II to about 90 percent. Due to the uncertain nature of the war, advancements started taking place in the psychology of operation. An astonishing statistic worth noticing was that the presence of mental health conditions rose from 88 percent to 96 percent for the American prisoners of war from Korea.

Because of the reason, of the stretching of the Vietnam war, the mental health issues of the armed personnel became extremely critical leading to the implementation of ASVABArmed Services Vocational Aptitude Battery. This was a consistent aptitude test tool, military psychologists depended on. After the Vietnam war, the regional conflicts arise, one such conflict was, Baader- Meinhoff bombing, Bosnia, Panama, the first Gulf- war saw the deployment of military psychologists to develop and implement mental health and terrorism combat techniques.

\section{The history of Indian Military Psychology}

The establishment of Military Psychology in India has been a relatively recent development. During the progression of the second World War, researchers found traces or the saplings of military psychology and research were sown in India. Just as in other countries, the psychologists here too faced numerous challenges in the establishment of a concrete psychological intervention programme.

A homogeneous system of selection, training, recruitment, machine allocation was supposed to be established with accord to keeping in mind the psychological processes and warfare. It is an understatement to say that a psychologically trained officer has an altogether different set of qualities which shape his/her personality holistically. Together the biggest challenge was to create a system so sound that after the amalgamation of the final training lessons and psychological exercises, what Indian forces get is a dedicated, tough-minded individual ready to sacrifice it all, but with a heart in its place.

Table-1 depicts a holistic chronological chain of events that shaped the present status of the military psychology for what it is today. We have the enormous defence research and development organization (DRDO), and Defence Institute of Psychological Research, a sister organization to DRDO, the aim of DIPR is to become an organization of excellence in the area of Military Psychology. The DIPR is responsible for providing a sure shot system of personnel selection based on using the standardized tests of intelligence, personality and aptitude to establish psychological preparedness and attributes expected of future Armed forces personnel.

Table 1: Depicts a brief chronological chain of important events in the history of Indian Military Psychology.

\begin{tabular}{|l|l|}
\hline Year & Events \\
\hline 1942 & $\begin{array}{l}\text { Recruitment of the Armed Forces Officers at the Directorate of Recruiting in the } \\
\text { Adjutant General's branch. }\end{array}$ \\
\hline 1943 & $\begin{array}{l}\text { The War Selection Officer Board was established in Dehradun for Psychological } \\
\text { procedure of selection. }\end{array}$ \\
\hline 1943 & $\begin{array}{l}\text { The Recruiting Directorate created a Selection of Personnel Directorate to initiate } \\
\text { research and innovation in the new techniques of selection. }\end{array}$ \\
\hline 1944 & A psychological methodology of the selection procedure was applied experimentally. \\
\hline
\end{tabular}




\begin{tabular}{|l|l|}
\hline Year & Events \\
\hline 1945 & The psychological method of selecting the other ranks was now applied functionally. \\
\hline 1949 & $\begin{array}{l}\text { Recommendation of the removal of psychiatric interview by the Ghosh Committee } \\
\text { and replacement by establishing a Psychological Research Wing. }\end{array}$ \\
\hline 1949 & Establishment of the Psychological Research Wing. \\
\hline 1950 & $\begin{array}{l}\text { An identification of about 39 qualities, categorized into 5 qualities was created for } \\
\text { officer's selection. }\end{array}$ \\
\hline 1950 & Interview technique was standardized. \\
\hline 1950 & Pilot Aptitude Test Battery conceptualized for aviation aptitude. \\
\hline 1952 & G.T.O technique was standardized. \\
\hline 1956 & Naval Psychological Research Unit was established, in Cochin. \\
\hline 1962 & Psychological Research Wing renamed as Directorate of Psychological Research. \\
\hline 1962 & $\begin{array}{l}\text { An applied psychology research wing under the DPR was especially formulated for } \\
\text { human engineering and psychomotor research. }\end{array}$ \\
\hline 1982 & $\begin{array}{l}\text { The Psychological method of recruitment was introduced for the infantry units on an } \\
\text { experimental level. }\end{array}$ \\
\hline & $\begin{array}{l}\text { Directorate of Psychological Research was renamed as Defence Institute of } \\
\text { Psychological Research. }\end{array}$ \\
\hline
\end{tabular}

The DIPR is the institute that ensures on the job fit, selection procedure, for the Armed Forces. Over the years, the DIPR has tried to focus more towards research and innovation purposes. The institution focuses on providing psychological research in training and selection purposes, leadership and effectiveness. The institution runs with a threedimensional approach: organizational behavior, personnel selection and human factors.

The DIPR has constructed and standardized various test batteries, analogies, teaching aptitude, English and other language proficiency tests, translators or recall and retention tests have also been adapted and formulated to fit the standards of the army selection processes. The SSB selection board at present uses thematic apperception test, word association test and situation reaction test as a part of a comprehensive psychological assessment procedure.

\section{Nature and Scope of Military Psychology}

The nature and scope of military psychology varies in its intensity and area of application as per the usage and requirements of the armed forces. The nature can be deemed as demanding and full of uncertainties where the military personnel have to be extremely cautious with the technicalities and the art of psychological warfare, in terms of planning, strategizing and implementing operations.

The recruitment and implementation strategies of the armed forces in India has grown and expanded manifold. The armed forces have evolved in their advanced method of selection and upgradations in the procedure over the years. Various tests, batteries and selection tests measuring the psychological aptitude of the officers and uniformed men have been adapted and standardized according to the psychological aptitude. Such a curriculum that imbibes psychological method of selection, training and recruitment has for sure given our country various batches of efficient and competent officers and uniformed personnel. These men and women have shown their courage, zeal and dedication towards the nation in various battles and wars fought post-independence. They have not only strengthened our armed force's structure but have also strengthened it by providing utter brilliance in tracking and decoding international diplomacy with various countries by dealing with conflicts both internal and external. 
The field of military psychology derives its parallel coincidence from the fields that are complimentary and dynamic in nature are sports psychology, police psychology as these fields too addresses the issues of perceptual processes and behavioral aspects. The clinical and intervention planning challenges also remain quite similar for these fields making it a possibility that these fields can complement and contribute each other's empirical significance (Miller,2008).

With the dynamic and advancing nature of military warfare, the role of military psychologists has been expanding and changing for the good. This gives them a career which is dynamic and challenging. In the present scenario, the military psychologists are not only engaged in assessment and intervention planning along side dealing with clinical issues and disorders but also in assisting in upgrading and strategizing a robust selection process. Today beyond selection and recruitment, the military psychologists in India are engaged in developing studying and assessing the psychological affect and effect of traumatic conditions the armed forces personnel face in testing times and situation of war. Traumatic experiences leading to the formation of post- traumatic stress disorder is the most common observation in the serving personnel and the veterans. The military psychologists are expected to deal with challenging situations with efficacy and efficiency.

The psychologists associated with the military and forces face a challenge in terms of ensuring a transparent and valid screening and selection procedure so that the armed forces may be blessed by competent officers fit mentally, physically and emotionally. Screening and looking out for such qualities and aptitude is a challenging affair because part of endurance and making it to the cut is also surviving the hard days at training. The military psychologists make sure that adequate research and analysis is carried on regularly to formulate or modify testing and selection procedures in the forces so that as the cognitive abilities and mutations of the candidates are advancing throughout the fore coming generations, the assessment and selection procedure also aligns with the needs and requirements of the forces.

\section{Military and Mental health - A brief literature review.}

The studies and research evidences in India related to mental health related disorders and its empirical prevalence in the Armed Forces in India is limited. While the reasons are by large unexplored, probably due to the rigid structural hierarchy of the armed forces system, many cases of clinical psychiatric disorders are dealt with easily within the military population by the military psychologists and psychiatrists at the Armed Forces hospital unit itself.

The research evidences as we discussed in the beginning of the section may also be limited pertaining to the social stigma attached with the armed forces personnel indicative of the fact that it might be not so manly to develop a psychiatric illness or a psychological ailment despite being trained and deemed mentally fit and sound. It raises many questions as to if the training wasn't strong enough to deal with the progression of the disorder or did our personnel failed to master their rigorous training lessons?

The answer lies in a simple rule of thumb that mental and psychiatric illnesses can occur anytime to anyone irrespective of their gender, age, socio economic strata or the professional field they are a part of. Especially so, that resilience building and addressing mental issues and conflicts in the Armed Forces is an important issue to look upon not only because our country stands on the shoulders of the giants, but also because if the mental health of the leading force of our country's personnel is sound and adaptive and the traumatic issues they 
face while being deployed in challenging situations is dealt with, the country is better able to decide, strategize, implement and run on resources with of course a better implementation of the art of psychological warfare.

Sinha (2021) studied the prevalence of suicide in the armed forces despite adequate pharmacological and psychological intervention. The study was conducted from 2014-2017 where some 16 suicide cases were assessed and studied at an undisclosed hospital with the help of semi-structural interviews, call records and personal diaries. Findings suggested that majority of the suicide were attempted using armed gunfire followed by a family history of depressive or suicide ideation. To conclude as hypothesized, stress of serving in the armed forces was not found to be associative of suicide attempts.

Bhat (2017) conducted and emphasized in his empirical evidence that due to increased and repetitive deployment in combat wars there are high chances that stress and mis conductive behaviors could find its root in the forces. Preventing, analyzing and managing these combat related stressful situations is taken well care by the military psychologists and psychiatrists. A huge role of pharmacological intervention is highlighted in the study.

Sharma (2015) aimed to study in depth the occupational stress in the armed forces and to provide strategies to combat occupational stress at workplace. In order to analyze the data with around 415 high rank armed forces personnel using factor analysis. Inefficient leadership, unsupportive colleagues, role ambiguity and conflict were some of the contributing factors of occupational stressors prevalent in the armed forces working officers. Pawar et.al (2014) aimed to analyze mental health stigma across 302 patients and about 98 caregivers where 90 percent of the sample size admitted experiencing mental health stigma and related issues. While another significant finding was that women were perceived to face more discrimination than men in mental health related issues.

Ryali et.al (2011) conceptualized studying the stress levels in armed forces personnel, where they attempted to provide research related review and strategies to combat stress some of which included increasing soldier- officer communicative transparency, establishing rest and recoup units in areas of operation, modification of pay distribution scales to name a few.

In the next section, we will discuss the initiatives and intervention measures taken by the armed forces in strengthening India's fight against COVID-19. This section indicates how the armed forces stays committed to the goal of "service before self".

\section{Indian Armed Forces and current deployment in combating the COVID-19 pandemic in India- Helping overcome the enormous National Pandemic.}

The armed forces have time and again proved their sheer zeal and courage in providing quick relief during various national natural disasters. With building dismantled bridges overnight, providing relief in earthquakes during Gujarat in 2001 or the Kashmir earthquake in 2005 , or providing relief and airlifting families in the 2013 Kedarnath floods, the Indian armed forces have time and again shown that when everything else fails, the system and the government can blindly rely on the armed forces. These instances mentioned might be limited but there have been various such instances where the armed forces have single handedly managed combating natural calamities with full vigor, responsibility and able hands, effectively and efficiently. 
The second wave of the Covid-19 pandemic has taken a huge toll on the economic, social and healthcare system of the country. We have evidently seen how the healthcare has been affected severely with the ongoing second wave of covid-19. The defence leadership is committed towards strategizing and allocating the covid-19 resources throughout the country with the help of its combat aircrafts, naval ships, and heavy-duty flying jets creating an overall connective network using their airbases for smooth transportation of the resources.

Below is the list of measures and interventions undertaken by the Armed Forces of India with regard to fighting the covid-19 pandemic.

- The Armed Forces Medical Services have always been committed towards building a strengthened strategy to prevent the spread of the virus, assisting in constructing a smooth demand and supply chain, and in managing risk mitigation.

- Many of the army cantonment and base hospitals have been converted to dedicated Covid Care Hospitals. These centers follow strict protocols and are separate from the main area of the hospital unit.

- The armed forces have ensured a homogeneous distribution of medical staff, attendants and health- care workers across the base and cantonment hospitals packed by adequate medical supply and A grade treatment facilities.

- Temporary hospital and quarantine facilities have been constructed by the Armed Forces by assisting the government across Gurugram.

- The DRDO in response to the second wave management has established a huge 1000 bed Covid-19 hospital facility well equipped by ICU and life support facility in the capital state DELHI.

- The aviation of the forces has been extremely fruitful and of use in maintaining the homogeneous distribution of covid supplies throughout the country. The light combat aircraft Tejas has been eventually roped in for the management and distributional purposes whereas $\mathrm{C}-17$ globe master is being specifically used for medical supplies and oxygen distribution.

- The Armed Forces have been constantly assisting in providing and aiding the oxygen supply to various states with the help of combat tankers, LCA and HCA. Some of the measures have been taken by the Armed Forces were decided upon the emergency transfer of powers considering the need to bridge the gap of critical care needs of the country.

- The DRDO has successfully able to launch an anti-viral drug named as 2-deoxy-Dglucose (2-DG) which after successful clinical trials have proved to shorten the stay at the hospital by a week in many clinical samples. The first batch of about 10,000 doses is expected to be released around May 22, 2021.

\section{CHALLENGES IN MILITARY PSYCHOLOGY}

Military psychologists and the field of military psychology are intertwined as it is a huge responsibility to maintain the confidentiality of the military personnel keeping the essence of personal experiences intact and still providing an intervention plan which not only treats the symptomatology but also provides client trust and confidentiality.

Sometimes details of covert operations elicit sensitive episodes of traumatic experiences the armed forces personnel are reluctant or resistant to share majorly because of the confidentiality among the units, the apprehension of sharing covert details about the operation that lead to the traumatic event or the episode that triggered the psychological issues post war. 
The challenge here is to break the resistance of the armed forces personnel who are trained to be mentally tough and stern in their approach. As loyalty towards the nation runs deep in the men in uniform, the reluctance during sessions may be evident more than the usual population. Having said that there needs to be a special dedicated team of mental health professionals so that a comprehensive addressal of psychological issues can be undertaken.

The field of military psychology is unique in itself as it deals with various underlying and overlapping sub fields of psychology per say. One such example could be leadership and organizational behavior where the uniformed personnel are taught the leadership skills and skills related to operations. Human resources and organization is a core skill apart from leadership avenues in the Armed Forces especially in India where the men in uniform have to be an epitome of courage, assertiveness, resilience, zeal, wit and altruism.

The ethical challenges here are many, to conclude some might evolve from the reluctance of the armed forces personnel while some might erupt from the inability of the psychologists to break the resistance due to better mental training and the stigma attached to therapeutic intervention and pharmacological intervention as well. The structural buildup of the forces follows a strict hierarchical pathway because of the confidentiality of the operational strategies and security issues related to the country.

Empirical evidences pertaining to the addressal of mental health issues in the Indian armed forces are limited whereas various official statistics are indicative of the fact that there is prevalence of developing at least one psychological disorder in the course of serving in the armed forces but such instances go under reported due in terms of methodological research evidences due to a closely knit confidential organizational structure.

Psychologically speaking, to ensure a smooth working of the sub-systems within the armed forces, timely addressal of mental health issues if any has to take place in the battalions and units of the forces. It is the duty of the recruited military psychologist and the psychiatrist to ensure a homogeneous working of the two as a team so that our men in uniform are better able to deal with mental health issues both psychologically and pharmacologically.

\section{DISCUSSION}

With this paper the author's aim was to analyze how the Indian military culture functions and what role psychology plays in its functioning. The armed forces have always displayed its zeal, sheer wit and courage in strengthening the structure of democratic country like India. The attempt is to explore in depth, the need of military psychology and how military psychologists or psychologists in general can help the military personnel during times of psychological distress. This research also provides ways in which the mental health professionals can strengthen this relationship with the armed forces of India.

The DIPR has constructed and standardized various test batteries, analogies, teaching aptitude, English and other language proficiency tests, translators or recall and retention tests have also been adapted and formulated to fit the standards of the army selection processes. The SSB selection board at present uses thematic apperception test, word association test and situation reaction test as a part of a comprehensive psychological assessment procedure. The psychologists associated with the military and forces face a challenge in terms of ensuring a transparent and valid screening and selection procedure so that the armed forces may be blessed by competent officers fit mentally, physically and emotionally. Screening and looking out for such qualities and aptitude is a challenging affair because part of 
endurance and making it to the cut is also surviving the hard days at training. The military psychologists make sure that adequate research and analysis is carried on regularly to formulate or modify testing and selection procedures in the forces so that as the cognitive abilities and mutations of the candidates are advancing throughout the fore coming generations, the assessment and selection procedure also aligns with the needs and requirements of the forces.

The studies and research evidences in India related to mental health related disorders and its empirical prevalence in the Armed Forces in India is limited. While the reasons are by large unexplored, probably due to the rigid structural hierarchy of the armed forces system, many cases of clinical psychiatric disorders are dealt with easily within the military population by the military psychologists and psychiatrists at the Armed Forces hospital unit itself.

The aviation of the forces has been extremely fruitful and of use in maintaining the homogeneous distribution of covid supplies throughout the country. The light combat aircraft Tejas has been eventually roped in for the management and distributional purposes whereas C-17 globe master is being specifically used for medical supplies and oxygen distribution. The Armed Forces have been constantly assisting in providing and aiding the oxygen supply to various states with the help of combat tankers, LCA and HCA. Some of the measures have been taken by the Armed Forces were decided upon the emergency transfer of powers considering the need to bridge the gap of critical care needs of the country.

The ethical challenges here are many, to conclude some might evolve from the reluctance of the armed forces personnel while some might erupt from the inability of the psychologists to break the resistance due to better mental training and the stigma attached to therapeutic intervention and pharmacological intervention as well. The structural buildup of the forces follows a strict hierarchical pathway because of the confidentiality of the operational strategies and security issues related to the country.

Empirical evidences pertaining to the addressal of mental health issues in the Indian armed forces are limited whereas various official statistics are indicative of the fact that there is prevalence of developing at least one psychological disorder in the course of serving in the armed forces but such instances go under reported due in terms of methodological research evidences due to a closely knit confidential organizational structure.

\section{CONCLUSION}

The history of military psychology dates back to the times of World War I and World War II when army Alpha and army beta tests were constructed by psychologists. The army Alpha test was constructed by Robert Yerkes along with his colleagues in the year 1917 to evaluate The US military recruits The US military recruits during World War I. The aim of this research is to understand, evaluate the need of military psychology and its scope and challenges face by the armed forces of India.

With this research article, the aim is also to highlight the qualitative relationship of psychology and military culture. With this paper the author aims to analyze how the Indian military culture functions and what role psychology plays in its functioning. The armed forces have always displayed its zeal, sheer wit and courage in strengthening the structure of Democratic country like India. The attempt is to explore in depth, the need of military psychology and how military psychologists or psychologists in general can help the military 
personnel during times of psychological distress. This research also provides ways in which the mental health professionals can strengthen this relationship with the armed forces of India.

The psychologists associated with the military and forces face a challenge in terms of ensuring a transparent and valid screening and selection procedure so that the armed forces may be blessed by competent officers fit mentally, physically and emotionally. Screening and looking out for such qualities and aptitude is a challenging affair because part of endurance and making it to the cut is also surviving the hard days at training. The military psychologists make sure that adequate research and analysis is carried on regularly to formulate or modify testing and selection procedures in the forces so that as the cognitive abilities and mutations of the candidates are advancing throughout the fore coming generations, the assessment and selection procedure also aligns with the needs and requirements of the forces.

\section{Future Scope and Implications}

Better qualitative and quantitative data can be analyzed with respect to psychological variables such as stress, trauma, depression, anxiety and neuropsychological issues pre and post on field operations.

The scope of this study is limited to qualitative data based on a mixed method qualitative analysis. Further researches can be conducted on the efficacy of the psychological tests of selection and on areas about how a shortage of mental and allied health professionals in the area of the Indian Armed Forces in itself is a matter of concern. The author agrees and endorses the fact that proper confidentiality and operational integrity has to be maintained following the operational structure of the forces, but we still need more mental health practitioners and researchers in the area of Military Psychology.

\section{AUTHOR DISCLAIMER}

The section "Military and Mental health - A brief literature review" highlights the need of timely addressal of mental health issues in the armed forces and it is an attempt to strengthen the use of research in this direction so that a strengthened intervention and balanced diagnostic classification can be made. By no means the lack of research evidence shows or indicates lack of general adaptability of the armed forces in dealing with mental disorders.

\section{REFERENCES}

Amit, K., Lisak, A., Popper, M., \& Gal, R. (2007). Motivation to lead: Research on the motives for undertaking leadership roles in the Israel Defense Forces (IDF). Military Psychology, 19, 137-160.

Banerji A. The armed forces medical services response to COVID-19. Indian J Public Health 2020;64: S94-5.

Bhat, P. S. (2017). Combat psychiatry: Indian perspective. Medical Journal Armed Forces India, 73(4), 404-406.

Boring, E.G. (Ed.). (1945). Psychology for the armed forces. Washington, DC: Infantry Journal.

Chakraborty, P. K. (2002). The significance of attempted suicide in armed forces. Indian journal of Psychiatry, 44(3), 277.

Defence Institute of Psychological Research. (2005). Development of computerised pilot selection system. (DIPR Technical Report). Delhi: DIPR. 


\section{Military Psychology- Need, Scope and Challenges}

Defence Institute of Psychological Research. (2007a). Development of a comprehensive battery of cognitive abilities for selection of candidates for commissioned ranks in the Armed Forces. (DIPR Technical Report). Delhi: DIPR.

Defence Institute of Psychological Research. (2008a). Development of new psychological test battery for the s election and trade allocation of other ranks in the Indian Army. (DIPR Technical Report). Delhi: DIPR.

Gupta, S., Kohli, K., Padmakumari, P., Dixit, P. K., Prasad, A. S., Chakravarthy, B. S., Shukla, R., Ghana, P., Mahapatra, D., \& Varadaraj, G. (2020). Psychological Health Among Armed Forces Doctors During COVID-19 Pandemic in India. Indian Journal of Psychological Medicine, 42(4), 374-378. https://doi.org/10.1177/0253717620934037

Johnson W.B., Landsinger K.L. (2017) Ethical Issues in Military Psychology. In: Bowles S., Bartone P. (eds) Handbook of Military Psychology. Springer, Cham. https://doi.org/10.1007/978-3-319-66192-6_8

Matthews, M. D., \& Laurence, J. H. (2012). Military psychology. In the Oxford Handbook of Military Psychology.

Moore, B. A., \& Barnett, J. E. (Eds.). (2014). Military psychologists' desk reference. Oxford University Press.

Mukherjee, S., Kumar, U., \& Mandal, M. K. (2009). Status of military psychology in India: A review. Journal of the Indian Academy of Applied Psychology, 35(2), 181-194.

Pawar, A. A., Peters, A., \& Rathod, J. (2014). Stigma of mental illness: A study in the Indian Armed Forces. medical journal armed forces india, 70(4), 354-359.

Ryali, V. S. S. R., Bhat, P. S., \& Srivastava, K. (2011). Stress in the Indian Armed Forces: how true and what to do? Medical journal, Armed Forces India, 67(3), 209.

Sharma, S. (2015). Occupational stress in the armed forces: An Indian army perspective. IIMB Management Review, 27(3), 185-195.

Sinha, A., Gupta, S., Ray, M., Kumar, S., \& Gupta, A. K. (2021). Lessons Learned from Psychological Autopsies in Armed Forces. Indian Journal of Psychological Medicine, 43(2), 150-153. https://doi.org/10.1177/0253717620950254

Spinrad, P.S. (1993). Patriotism as pathology: Anti-veteran activism and the VA. Journal of the Vietnam Veterans Institute, 2(1), 42-70.

Williams, A. M., Ericsson, K. A., Ward, P., \& Eccles, D. W. (2008). Research on expertise in sport: Implications for the military. Military Psychology. 20, 123-145.

\section{Acknowledgement}

The author(s) appreciates all those who participated in the study and helped to facilitate the research process.

\section{Conflict of Interest}

The author(s) declared no conflict of interest.

How to cite this article: Sharma M. (2021). Military Psychology- Need, Scope and Challenges. International Journal of Indian Psychology, 9(2), 1365-1375. DIP:18.01.141.20210902, DOI:10.25215/0902.141 